\title{
Programa Municípios Verdes: políticas públicas para mitigação de degradação ambiental no município de Paragominas (PA)
}

O Programa Municípios Verdes foi criado no estado do Pará no ano de 2011, inspirado na experiência bem-sucedida do município de Paragominas, que adotou procedimentos para a regularização ambiental em resposta à sua inclusão na lista do Ministério do Meio Ambiente. Paragominas foi o primeiro município da Amazônia a sair da lista do desmatamento, recebendo premiações como a de Chico Mendes no ano de 2010, em que são levados em consideração os critérios de participação social, impacto social, ambiental, dentre outros. O presente artigo teve como objetivo fazer um estudo sobre a implantação do Programa Municípios Verdes como política pública para mitigação de degradação ambiental no Município de Paragominas, Pará, na perspectiva dos moradores. Em termos metodológicos, a pesquisa foi quali-quantitativa, bibliográfica e com atividades de campo. A coleta de dados foi realizada por meio de um formulário nos meses de fevereiro e março de 2018, com 60 respondentes. Os resultados indicaram que os problemas de maior gravidade em Paragominas são: contaminação de solos e degradação ambiental, seguidos do uso excessivo de agrotóxicos e os lixões. Em nível intermediário, destacam-se a falta de saneamento básico e poluição da água, bem como, a falta de Educação Ambiental e de arborização. Os problemas de menor gravidade para a amostra são o desmatamento e escassez de água potável. Esses resultados indicam que a implantação do PMV foi importante para conter os problemas ambientais em Paragominas, mas novas ações precisam ser adotadas no sentido de mitigar os impactos ambientais que ainda persistem no município.

Palavras-chave: Modelo de desenvolvimento; Degradação ambiental; Sociedade.

\section{Green Municipalities Program: public policies to mitigate environmental degradation in the municipality of Paragominas (PA)}

The Green Municipalities Program was created in the state of Pará in 2011, inspired by the successful experience of Paragominas municipality, which adopted procedures for environmental regularization in response to its inclusion in the list of the Ministry of Environment. Paragominas was the first municipality of the Amazon to leave the list of deforestation, receiving awards such as Chico Mendes in 2010, which take into account the criteria of social participation, social and environmental impact, among others. This article aimed to study the implementation of the Green Municipalities Program as a public policy for mitigating environmental degradation in Paragominas, Pará, from the perspective of residents. In methodological terms, the research was quali-quantitative, bibliographic and with field activities. Data collection was performed using a form in February and March 2018, with 60 respondents. The results indicated that the most serious problems in Paragominas are: soil contamination and environmental degradation, followed by the excessive use of pesticides and dumps. At an intermediate level, we highlight the lack of basic sanitation and water pollution, as well as the lack of Environmental Education and afforestation. The minor problems for the sample are deforestation and shortages of drinking water. These results indicate that the implementation of the PMV was important to contain environmental problems in Paragominas, but new actions need to be taken to mitigate the environmental impacts that still persist in the municipality.

Keywords: Development model; Ambiental degradation; Society.

Topic: Desenvolvimento, Sustentabilidade e Meio Ambiente

Reviewed anonymously in the process of blind peer.

Jamille Silva Rodrigues de Souza

Universidade Federal do Pará, Brasil

http://lattes.cnpq.br/0738186667963141

ja milly12@hotmail.com

Priscila Sanjuan de Medeiros Sarmento (iD

Universidade Federal do Pará, Brasil

http://lattes.cnpq.br/5138782013605157

http://orcid.org/0000-0002-5001-9573

priscilasanjuanbio@yahoo.com.b

Aldo Nascimento Ponte

Faculdade de Tecnologia de Indaiatuba, Brasil

http://lattes.cnpq.br/0353109973808848

aldopontes@hotmail.com
Received: 15/07/2018

Approved: 19/10/2018

Altem Nascimento Pontes (it)

Universidade Federal do Pará, Brasil

http://lattes.cnpq.br/5993352890364998

http://orcid.org/0000-0002-9001-4603

altempontes@hotmail.com
Referencing this:

SOUZA, J. S. R.; SARMENTO, P. S. M.; PONTES, A. N.; PONTES, A. N. Programa Municípios Verdes: políticas públicas para mitigação de degradação ambiental no município de Paragominas (PA). Natural Resources, v.8, n.2, p.52-59, 2018. DOI: http://doi.org/10.6008/CBPC2237-9290.2018.002.0006 


\section{INTRODUÇÃO}

No âmbito estadual, o Programa Municípios Verdes (PMV) apresenta-se como uma transformação significativa contra o desmatamento (COSTA et al., 2015), sendo implantado pelo Governo do Estado do Pará, juntamente com órgãos públicos, privados e municipais. Foi instituído pelo Decreto Estadual $n^{\circ} 54 / 2011$, de 30 de março de 2011 (PARÁ, 2011), e tem por finalidade consolidar o desenvolvimento sustentável na Amazônia (PARÁ, 2013). O PMV apresenta 11 objetivos, entre eles: "intensificar a atividade agropecuária nas áreas consolidadas; reduzir o desmatamento e a degradação ambiental e promover ações de Educação Ambiental" (PARÁ, 2013).

O Instituto do Homem e Meio Ambiente da Amazônia (Imazon), definiu as principais ações para um Munícipio ser Verde, que vão desde a redução do desmatamento, até uma gestão municipal de meio ambiente estruturada e transparente (GUIMARÃES et al., 2011). Neste sentido, para o Imazon, o PMV deve promover uma ampla e dinâmica relação sustentável entre as diferentes formas de vida, a fim de reduzir os danos ambientais sem deixar de proporcionar melhorias à qualidade de vida da população.

O desmatamento é um dos fatores que mais causam danos ao meio ambiente. Para o Ministério Público Federal, a extração ilegal da madeira, é uma prática extremamente nociva, uma vez que é seguida por queimadas, e posteriormente, pelo estabelecimento da área convertida, ocasionando perda da biodiversidade, além de movimentar esquemas criminosos (BRASIL, 2015). Essa perda de diversidade ocasiona o que Pereira Junior et al. (2017), em seus estudos, chama de degradação ambiental gerada em função da extração dos recursos nativos.

Dentro desse contexto de desequilíbrio ambiental, o município de Paragominas, no Estado do Pará, no ano de 2010, segundos dados do Fundo Vale, mostrou-se como pioneiro da região amazônica ao sair da lista dos municípios que mais desmatavam. De acordo com os dados do Instituto Nacional de Pesquisas Espaciais (INPE), o desmatamento no Município de Paragominas apresentou uma queda nos últimos anos, sendo que no ano de 2016 houve uma redução de 19\% em comparação ao ano anterior (INPE, 2017).

Para Villela (2010), Paragominas obteve êxito com o PMV devido a fatores como: queda do desmatamento, participação popular, efetividade das ações e implantação de políticas de Educação Ambiental, garantindo-Ihe assim premiações como a de Chico Mendes no ano de 2010 (BRASIL, 2010). Afirma ainda que o Município soube envolver diretamente a população local na busca de soluções duradouras.

Dessa forma, todos esses avanços representam um marco no espaço-tempo do Município. Partindo desse pressuposto, o objetivo desse trabalho foi fazer um estudo sobre a implantação do Programa Municípios Verdes como política pública para mitigação de degradação ambiental no Município de Paragominas, Pará, na perspectiva dos moradores.

\section{MATERIAIS E MÉTODOS}

\section{Área de Estudo}

A área de estudo corresponde ao município de Paragominas, no estado do Pará, fundado em 1965, Lei no884/2015 (PARÁ, 2015). Conforme dados do IBGE (2016), é um município com uma população estimada 
em 103.775 mil habitantes, formada por colonizadores mineiros, goianos, baianos e paulistas, e localiza-se às margens da rodovia Belém-Brasília (BR-010) sob as coordenadas de $02^{\circ} 59^{\prime \prime} 45^{\prime \prime}$ S e $47^{\circ} 21^{\prime} 10^{\prime \prime} \mathrm{W}$, ilustrado na figura 1). As principais atividades econômicas na região são a pecuária, indústria madeireira, produção de carvão, agricultura de pequena, média e grande escala e mineração de bauxita, que são as principais fontes do Produto Interno Bruto (PIB), conforme afirma Santos et al. (2017). De acordo com estudos de Villela (2010), Paragominas já teve metade do seu território desmatado ao longo de décadas, mas a implantação do PMV tem contribuído para redução deste nível de degradação ambiental.

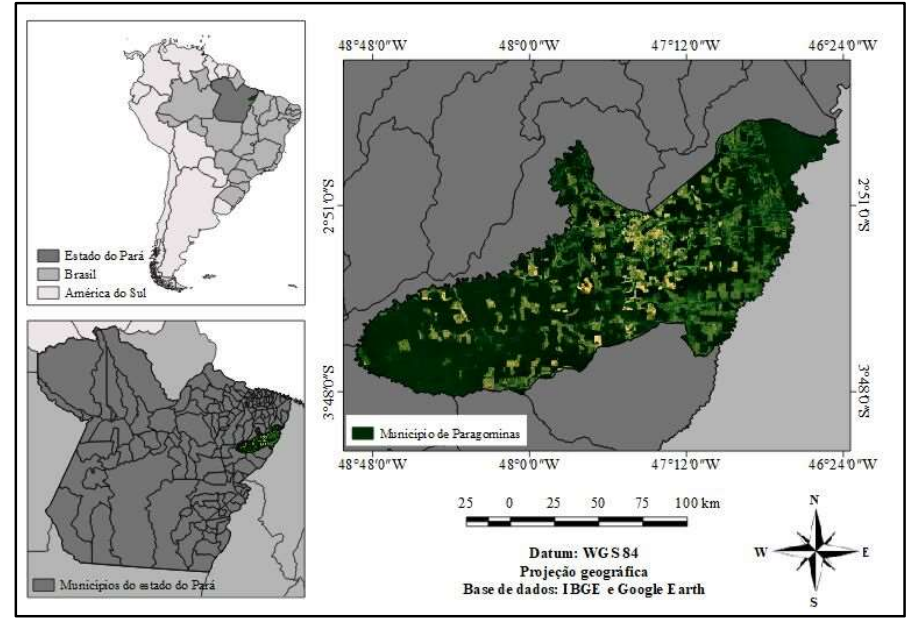

Figura 1: Mapa de localização da área de estudo.

\section{Pesquisa, Amostra e Amostragem}

Quanto a abordagem, a presente pesquisa foi quali-quantitativa. Em se tratando da natureza, tratase de uma pesquisa básica. No que concerne aos objetivos, esta pesquisa é do tipo exploratória. Em relação aos procedimentos, a pesquisa foi bibliográfica e documental, com atividades de campo (SEVERINO, 2016). A amostra foi constituída de 60 informantes residentes na zona urbana do município de Paragominas. A amostragem foi completamente aleatória.

\section{Coleta e Análise de Dados}

A coleta de dados foi realizada por meio de um formulário, com perguntas abertas e fechadas, nos meses de fevereiro e março de 2018. Todos os participantes desta pesquisa assinaram o Termo de Consentimento Livre e Esclarecido. Na análise de dados foi empregada estatística descritiva, para obtenção de médias e frequências e posterior elaboração de gráficos e tabelas. Além disso, empregou-se também estatística multivariada, na forma de Análise de Componentes Principais (PCA) e Análise Hierárquica de Agrupamento (HCA), na perspectiva de avaliar as similaridades entre as observações e variáveis empregadas na análise.

\section{DISCUSSÃO TEÓRICA}

No estudo, observou-se que em relação ao gênero, 55,0\% dos informantes eram do gênero feminino, o que indica a predominância das mulheres na amostra. No que concerne à idade, a grande maioria dos 
respondentes, $71,7 \%$, foi constituída de indivíduos adultos. Em se tratando da escolaridade, a amostra desta pesquisa é bem diversificada, prevalecendo, no entanto, indivíduos com formação de ensino superior incompleto $(30,0 \%)$ e completo $(15,0 \%)$. A Figura 2 apresenta dados sociais - gênero, idade e escolaridade da amostra que participou da presente pesquisa.

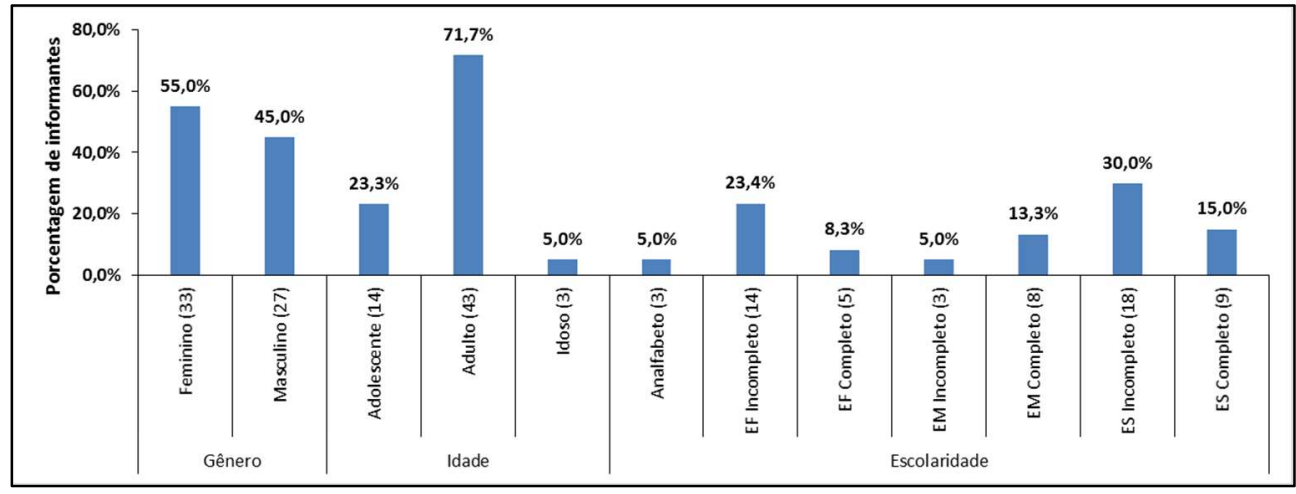

Figura 2: Perfil social da amostra da pesquisa.

Quando aos moradores do município que participaram da pesquisa, foram questionados se tinham conhecimento que Paragominas é um Município Verde, 86,7\% afirmaram que sim (figura 3). Cerca de 58,4\% dos informantes disseram que a Prefeitura de Paragominas conscientizou a população local sobre a implantação do PMV, e outros $56,7 \%$ asseguraram que a Prefeitura de Paragominas implantou políticas públicas de sensibilização relativas à Educação Ambiental, conforme se pode ver na figura 3.

De acordo com a amostra, a população local tem plena consciência de que Paragominas ostenta o posto de Município Verde, o que demonstra que houve algum processo de sensibilização no sentido de divulgar esta importante conquista para os munícipes. $O$ fato de apenas $58,4 \%$ de a amostra afirmar que a Prefeitura implantou políticas públicas de sensibilização sobre a implantação do PMV demonstra que políticas privadas, provenientes do terceiro setor, como as organizações não governamentais, além da mídia local, podem também ter contribuído com a divulgação sobre a implantação do PMV. A promoção de ações de Educação Ambiental é um dos 11 objetivos do PMV, mas um pouco mais de $40 \%$ da amostra não sabe ou não teve conhecimento sobre essa importante política pública.

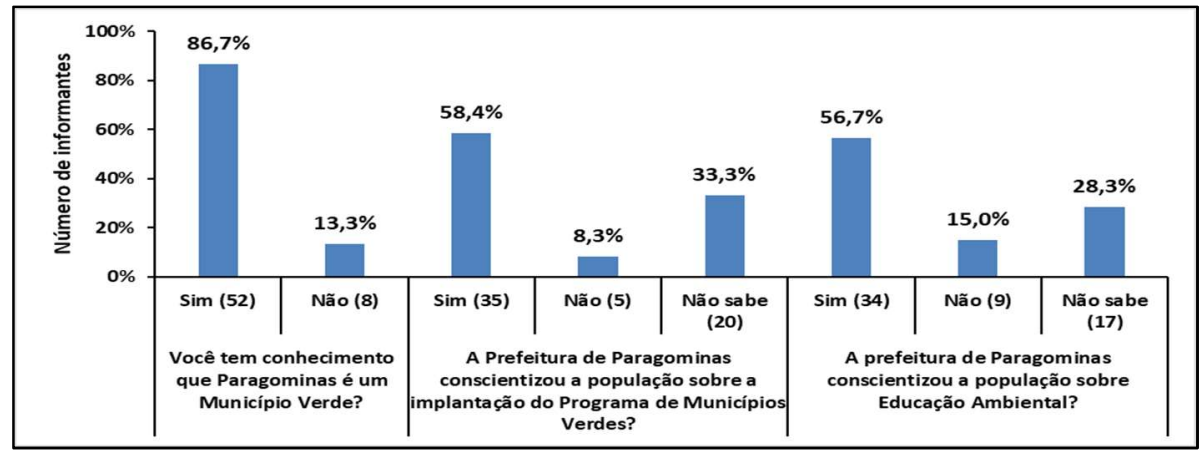

Figura 3: Conhecimento de moradores de Paragominas sobre questões relativas ao Programa Municípios Verdes.

A análise de componentes principais (PCA) foi empregada aos resultados provenientes da avaliação dos informantes da pesquisa sobre os principais problemas ambientais no município de Paragominas. Para isso, foi elaborado um gráfico de scores (observações) da análise de componentes principais, conforme indica 
a figura 4. Nesta, as duas primeiras componentes, PC1 e PC2, foram escolhidas pois representam a combinação linear de maior variância e explicam $100 \%$ da variação dos dados coletados.

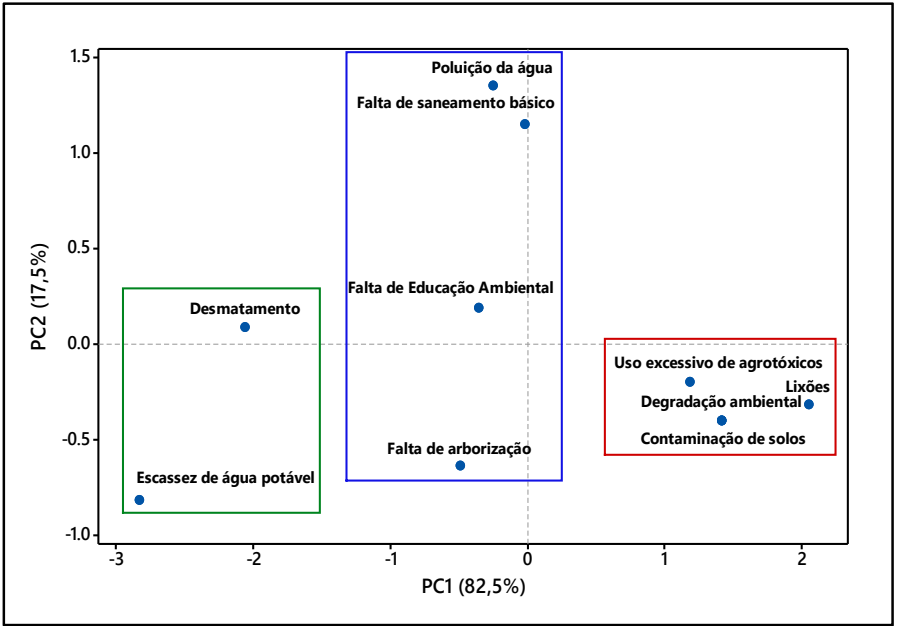

Figura 4: Gráfico de scores (observações) da análise de componentes principais dos principais problemas ambientais no município de Paragominas.

Os dados da Figura 4 foram confrontados com o dendrograma relativo aos principais problemas ambientais que afetam o município de Paragominas na perspectiva dos informantes da pesquisa (Figura 5). As figuras 4 e 5 demonstram claramente a formação de três grupos envolvendo os problemas ambientais que mais afetam os munícipes sob a ótica da amostra.

De acordo com a Figura 5, a contaminação dos solos e a degradação ambiental são os maiores problemas de Paragominas, pois apresentam as maiores similaridades. A esse grupo, juntam-se o uso excessivo de agrotóxicos e os lixões como outros importantes problemas ambientais. Um segundo grupo é formado pela poluição da água e falta de saneamento básico com maiores similaridades, associado à falta de Educação Ambiental e de arborização como problemas ambientais que afetam a população local. O terceiro grupo formado está relacionado com desmatamento e escassez de água potável, que são as menores preocupações da amostra por apresentarem as menores similaridades.

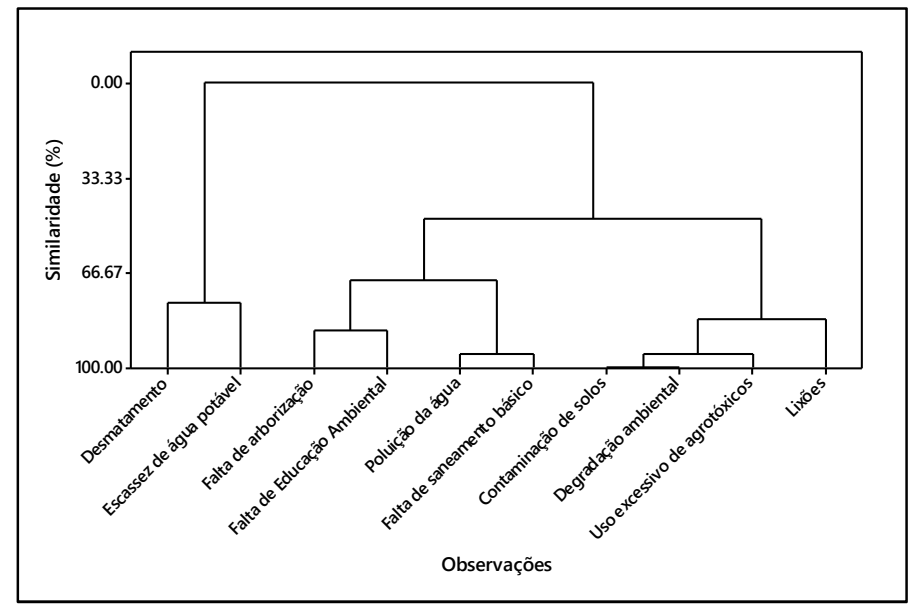

Figura 5: Dendrograma relativo aos principais problemas ambientais que afetam o município de Paragominas na perspectiva dos informantes da pesquisa. 
Conforme dados do IBGE (2015), o município de Paragominas é um grande produtor de arroz, milho e soja no estado do Pará, sendo assim, possui uma grande área de plantações com diferentes culturas, tendo a soja como destaque. Segundo estudos de Alves et al. (2014), o avanço da plantação de soja no município de Paragominas evidencia uma situação de alerta devido ao manejo do solo relacionado à esta monocultura, onde se utiliza uma quantidade expressiva de agrotóxicos e que, sem o devido controle, ocasiona degradações ambientais, como contaminação do solo e do manancial subterrâneo. Esses fatos justificam a preocupação dos moradores de Paragominas com o uso excessivo de agrotóxicos e com a contaminação de solos.

Segundo dados do último censo do IBGE, em 2010, Paragominas apresenta cerca de $12,4 \%$ de domicílios com sistema de esgoto sanitário adequado. Essa pouca cobertura de saneamento básico reforça a ideia de que os municípios brasileiros caminham vagarosamente rumo a universalização deste serviço (BANDEIRA et al., 2016).

Em 2016, segundo dados do Sistema Nacional de Informações sobre o Saneamento, esse cenário de precariedade em Paragominas não se alterou, pois, a população total atendida com esgotamento sanitário era de apenas 11.840 habitantes. Com os resultados encontrados neste estudo é possível observar que, mesmo sendo uma situação rotineira e muito presente no dia a dia de grande parte da população brasileira, a falta de saneamento básico é reconhecida pela maioria como um problema ambiental.

Observa-se ainda que, a necessidade de uma política mais efetiva de Educação Ambiental para a população, os lixões, e a falta de arborização representaram questões pertinentes de problemas no município. Sauvé (2016) sinaliza a importância da Educação Ambiental para promover o sentimento de pertencimento com o local, gerando uma identidade social que favorecem abordagens críticas e colaborativas das realidades socioeconômicas e ambientais (JACOBI, 2002; SAUVÉ, 2016).

Outro agravante evidenciado por meio dos dados coletados diz respeito à presença de lixões em Paragominas, ocasionados pela necessidade de implantação de políticas públicas voltadas para o saneamento, falta de medidas de gerenciamento de resíduos sólidos, bem como, pela implantação de coleta seletiva no município (GONÇALVES, 2017).

No município, apenas $12,9 \%$ dos domicílios urbanos em vias públicas apresentam arborização e 5,1\% dos domicílios urbanos em vias públicas têm urbanização adequada (IBGE, 2010). Esses dados reforçam a preocupação dos residentes com a falta de arborização em Paragominas. Um fator que chama atenção neste trabalho é a pouca relevância dada pelos participantes da pesquisa em relação a temas como desmatamento e escassez de água potável. Nobre (2014) afirma que o desmatamento tem implicação direta na interrupção da precipitação e, sem a chuva, não há água doce para ser armazenada nos oceanos subterrâneos. Além disso, a pouca importância dada à escassez de água potável pode ser compreendida porque o munícipio possui uma Agência de Saneamento - a SANEPAR -, e, de acordo com o SNIS (2016), o percentual da população atendida com sistema de água e esgoto é de aproximadamente 88,66\%. 


\section{CONCLUSÕES}

De acordo com a amostra desta pesquisa, a grande maioria dos munícipes de Paragominas tem pleno conhecimento sobre a implantação do PMV. Os munícipes informaram que os problemas ambientais de maior gravidade em Paragominas são: contaminação de solos e degradação ambiental, seguidos do uso excessivo de agrotóxicos e dos lixões. Em nível intermediário, destacam-se a falta de saneamento básico e poluição da água, bem como, a falta de Educação Ambiental e de arborização. Os problemas de menor gravidade para a amostra são o desmatamento e escassez de água potável. Com isso, conclui-se que, a implantação do Programa Municípios Verdes, no município de Paragominas, ainda não alcançou seu principal objetivo, uma vez que a população ainda aponta a degradação ambiental com um dos principais problemas do município.

No entanto, a implantação do PMV foi importante para conter os problemas ambientais em Paragominas - principalmente o desmatamento, pois até 2010 Paragominas estava na lista de municípios que mais desmatavam a Amazônia oriental -, mas novas ações precisam ser adotadas no sentido de mitigar os impactos ambientais que ainda persistem no município. Essas ações perpassam pela fiscalização no cumprimento da legislação, pela atribuição de multas aos que descumprirem os marcos regulatórios e políticas efetivas de Educação Ambiental para todos os munícipes de Paragominas.

\section{REFERÊNCIAS}

ALVES, L. W. R.; CARVALHO, E. J. M.; SILVA, L. G. T.. Diagnóstico agrícola do município de Paragominas (PA). Brasília: Embrapa Amazônia Oriental, 2014.

BANDEIRA, O. A.; ALVES, O. R.; ALVES, R. M.; GONÇALVES, L. M.; MORAES, L. M.. Análise dos serviços de saneamento básico em Goiânia (GO). Enciclopédia Biosfera, Goiânia, v.13 n.24, p.159, 2016.

BRASIL. Ministério do Meio Ambiente. Perfis dos vencedores do Prêmio Chico Mendes. Brasília: MMA, 2010.

BRASIL. Ministério Público Federal. Roteiro de Atuação Desmatamento. Brasília: MPF, 2015.

COSTA, J.; FLEURY, M. F.. O Programa 'Municípios Verdes': Estratégias de Revalorização do Espaço em Municípios Paraenses. Ambiente \& Sociedade, v.18, n.2, 2015.

GONÇALVES, K. S.. Proposta de um plano de gerenciamento de resíduos sólidos para uma unidade de secagem e armazenamento de grãos no município de Paragominas (PA). Monografia (MBA em Gestão Ambiental) Universidade Federal do Paraná, Curitiba. 2017.

GUIMARÃES, J.; VERÍSSIMO, A.; AMARAL, P.; DEMACHKI, A.. Municípios Verdes: Caminhos para a sustentabilidade. Belém: Imazon, 2011.

IBGE. Indicadores. Estatística da produção pecuária. Rio de Janeiro: IBGE, 2016.

IBGE. Instituto Brasileiro de Geografia e Estatística. Histórico de Paragominas. Rio de Janeiro: IBGE, 2010.
IBGE. Instituto Brasileiro de Geografia e Estatística. Histórico de Paragominas. Rio de Janeiro: IBGE, 2015.

INPE. Instituto Nacional de Pesquisas Espaciais. Atlas Brasileiro de Energia Solar. São José dos Campos: INPE, 2017.

JACOBI, P.. Educação ambiental: o desafio da construção de um pensamento crítico, complexo e reflexivo. Educação e Pesquisa, n.2, 2002.

NOBRE, A. D. O futuro climático da Amazônia. Relatório de avaliação científica. Articulación Regional Amazônica, v.31, 2014.

PARÁ. Decreto $\mathbf{n} . \mathbf{5 4}$ de $\mathbf{2 9}$ de março de 2011. Institui o Programa de Municípios Verdes - PMV no âmbito do Estado do Pará e dá outras providências. Belém: DOE, 2014.

PARÁ. Lei n.884/2015. Dispõe sobre a alteração, atualização e consolidação da legislação previdenciária do Município de Paragominas. Paragominas: DOE, 2015.

PARÁ. Portaria n.07/2013-PMV de 14 de junho de 2013. Declara a relação dos municípios aptos a receberem a prioridade prevista no Decreto no 740 , de 29 de maio de 2013, que dispõe sobre o apoio e incentivos aos municípios que atendem as metas do Programa Municípios Verdes PMV. Belém: DOE, 2013.

PEREIRA JUNIOR, A.; PEREIRA, R. E.. Degradação ambiental e a diversidade biológica/biodiversidade: uma revisão 
integrativa. Enciclopédia Biosfera, Goiânia, v.14, n.26, p.922-937, 2017.

SANTOS, M. E.; SANTOS, A. A. F.; GOMES, N. C. V. M.; SANTOS, C. V.; NEVES; R. R.. Análise espacial das ações do programa 'Municípios Verdes': estudo de caso no município de Paragominas (PA). Revista Brasileira de Gestão Ambiental, Pombal, v.11, n.2, p.21-35, 2017.
SAUVÉ, L.. Viver juntos em nossa terra: desafios contemporâneos da educação ambiental. Revista Contrapontos, Itajaí, v.16, n.2, p.288-299, 2016.

SEVERINO, A. J.. Metodologia do Trabalho Científico. São Paulo: Cortez, 2016.

VILELLA, M.. Paragominas: ainda é possível. Revista Página, v.22, n. 48,2010

A CBPC - Companhia Brasileira de Produção Científica (CNPJ: 11.221.422/0001-03) detém os direitos materiais desta publicação. Os direitos referem-se à publicação do trabalho em qualquer parte do mundo, incluindo os direitos às renovações, expansões e disseminações da contribuição, bem como outros direitos subsidiários. Todos os trabalhos publicados eletronicamente poderão posteriormente ser publicados em coletâneas impressas sob coordenação da Sustenere Publishing, da Companhia Brasileira de Produção Científica e seus parceiros autorizados. Os (as) autores (as) preservam os direitos autorais, mas não têm permissão para a publicação da contribuição em outro meio, impresso ou digital, em português ou em tradução. 